\title{
Value Management Practices on Major Construction Projects and Green Building
}

\begin{abstract}
The paper starts with background information on value management (VM) in the construction industry and current development situation of the green building industry, and costs and profitability of green buildings. The paper continues with detailed analyses of the findings, covering new developments and perceptions of VM, and applications of VM in the industry. The paper also reports case studies on the practices adopted in the planning and design management phase of SIPO Guangdong Patent Examination Cooperation Center and in the construction management phase of Guangzhou International Bio-Island Standard Property Unit II project. As revealed by the practices, the value-adds and savings in construction costs through the application of VM are important for the developers, and the contributions of VM application in green building projects are significant to achieving the expected targets and to resolving the design and construction challenges encountered in the development of green building industry. And the paper presents, findings on how VM can improve construction management and coordination of several ongoing construction projects and on how VM can be systematically implemented by phases, and discussions on other potential benefits of using VM systems.
\end{abstract}

Keywords: value management (VM), VM theory and practices, Chinese construction industry, green buildings

\section{Introduction}

In recent years, the international construction industry is showing gradually increasing trends toward green and

Manuscript received November 10, 2015; accepted March 20, 2016

Ru-jiang Zhao ( $ه)$

The Construction Command Center of Sino-Singapore Guangzhou Knowledge City, Guangzhou 510555, China

Email: res520@126.com

Wung Hee Moh

Singbridge Corporation Pte Ltd, Singapore

Email: wunghee.moh@ascendas-singbridge.com intelligent building construction. Under the advocacy of the governments of various nations, there are new developments and improvements of a series of international green and intelligent building construction standards and certifications. Following a series of new breakthroughs by the global construction industry toward green and intelligent development, there are new innovations and applications of project management models. In particular, value-based project management systems have been further promoted and enhanced in the international construction industry (Liu \& Li, 2008; SAVE International, 2007). In this connection, building owners have been playing an important role in construction project management. And in this new era of the construction industry, they have a major role in the establishment of advanced robust project management system that is well adapted to industry development, especially in promoting value-based project management in innovations of and applications for largescale construction projects. With high numbers of highperformance buildings and major complex projects, more and more owners are now placing emphasis on customer satisfaction after taking over of the buildings and realization of their life-cycle values, hence value-based project management pertaining to these two aspects has gradually attracted the attention of construction industry experts (Shi, 2014; Tong, 2008). In fact, when the construction project management encompasses environmental protection, value orientation, cultural and aesthetic, social relations, interests of all parties and other factors, there may be deviation and impacts on the projects' investment values. The introduction of value management (VM) is to ensure that the construction project owners can consistently implement investment concepts and successfully realize their investment objectives and the full lifecycle value upon completion. In the absence of an effective scientific approach of systematic management methodology to guide and coordinate the projects from initial consultation, design through construction, it will be difficult to consistently implement the investment concept and fully realize the investment objectives and life-cycle value over the long process of construction. This is because the lack of a clear theoretical and decision methodology, 
the owners might not be well guided to best manage project expenses and achieve good investment values. Based on narrowly focused targets at the preliminary and construction stages, for example, some owners might take the simplistic preference of low-priced bids and modifications rather than the best values of the buildings. In reality, unrealistically low-priced bids could, during the construction stage, give rise to unreasonable contract variations that might ultimately result in increased project costs; and construction quality could be affected and investment values jeopardized, especially when the requested variation increases are non-feasible or unacceptable. An international civil engineering consulting firm Mott MacDonald has put forth a research report to the British Ministry of Finance, finding that most western building owners had generally underestimated the construction costs, while the adoption of value-based project management could effectively reduce costs significantly and realize the investment asset and life-cycle value of the construction.

In green building project management, China's development of the green building industry has started relatively more recently. The supporting mechanisms and regulations are being built up, although its pace and standards of development vary over localities. To speed up the development of the green building industry, it is beneficial to learn from the head-starts and experience of the management and implementation of the current international green building development (Jiang, Cheng, Gao, Guo, \& Deng, 2013; McGraw Hill Construction, 2013). China's Evaluation Standard for Green Building defines the green building as one that "in the whole life cycle of the building, maximizes conservation of resources (energy, land, water, materials), protects the environment and reduces pollution, provides people with healthy, practical and efficient use of space, all in sustainable harmony with nature" (Ministry of Housing and Urban-Rural Construction, 2014). It is useful to relate this to other professional descriptions of green buildings in the international industry. Some experts describe the green building as one that is accelerating environmental, economic and health enhancements, and functionally surpassing the traditional building in its design, construction and use. Some experts describe the green building as one that encompasses environmental protection considerations throughout the whole process of the project implementation, entailing ecological, energyefficient and sustainable methodologies in its meticulous design, construction and operation, entailing resourcerecycling. There are also experts who describe the green building as one that, through better design, construction, operation, maintenance and even future demolition, increases efficiency in use of energy, water and materials and reduces adverse impacts on the building users and environment. With these references, green building construction can be deemed as that, throughout the wholeprocess from concept, design, construction, operation, until the re-use and demolition phases, entails the application of environmental protection, health consideration, energy efficiency and sustainable living concepts to achieve exceedingly enhanced construction project benefits. Green building, in environmental, health, energy efficiency and sustainable development aspects, is focused on improving the investment value and the life-cycle value of the project. By contrast, some traditional approaches, at times guided by relatively fragmented design, construction and operation management philosophy, might not well grasp the main value chain from beginning to end for comprehensive management of the entire green building projects (Xue, 2012). With the green building development, the means to enhance the investment value of green buildings and the life-cycle project value has attracted more and more attention (Wang \& Yuan, 2011). For green building construction management, in the lack of clear theoretical and decision methodologies, there could be inadequate clarity in managing the relationship between project spending and investment value of the project, with potentially adverse management and decision errors that undermine project values and impair the functionality. Therefore, the induction of VM will enable closer fullprocess management of green building project to effectively achieve successful project completion (Yan, Zheng, Wang, \& Gu, 2013).

\section{Background of VM for large-scale project implementation}

While experts are considering how to strengthen the establishment of the whole-process VM, various countries in the world are carrying out further systemization and IT enhancement of project design and construction management. Advanced foreign countries and regions including Germany, Britain and Singapore have implemented multidimensional Building Information Modeling (BIM) system. Among them, in Singapore for example, the Building \& Construction Authority (BCA) had specified that from July 2013 onwards, all construction projects exceeding $20,000 \mathrm{~m}^{2}$ in floor area are to be submitted to the BCA in BIM format. There is commercially available software including Bentley, Tekla, Auto desk and other BIM project management software, developing from the "3D stereoscopic" to the "4D stereoscopic + Time Dimension," "5D stereoscopic + Time + Cost Control Dimensions," and further enriched multi-dimensional models. And many design institutes are also setting up dedicated design teams to carry out BIM model-generation works. Those under research include Finite Element Architectural (FEA) design system development using CAD-based IFC platform. These products and research are naturally driven by the project managers' own usage consideration and management of the project information, though possibly varying in their extents of entailing elements of the value-based management system. But it can be envisioned that, with the 
gradual promotion and adoption of BIM technology, various value-based management techniques could be developed on the BIM platform (for example, GDSSbased multi-party project VM systems). BIM technology also allows the VM team to make rational decision in the three-dimensional visualization environment, avoiding past errors caused by subjective decisions. Ultimately however, while BIM as a multi-dimensional informational technology is definitely a great enabling tool for the purpose, use of any such tools is not by itself a sufficient condition to realize comprehensive systematic VM tasks. Importantly, there remains the need for present project management structure, processes and decision methodology to undergo rational exploration, practical implementation and innovation of value-based management.

In large-scale construction project management under our existing project management model, there sometimes exists the situation of incomprehensive whole-process system and overall VM in decision-making, design and construction. This could at times result in these large-scale projects being implemented by the various units working independently, concerned with their separate functional goals while neglecting the value of overall project management and monitoring control. Over the past few decades, China has taken steps to improve and enhance models and systems for the management of large construction project. For example, since 1988, China has through the 3-stage process of pilot phase, steady development and full implementation, put in place the project supervision system. Looking ahead, more valuebased management processes are needed as the country undertakes vigorous development of large, complex, highperformance and green buildings. This will enhance awareness of $\mathrm{VM}$ of the projects, minimize inadvertent value deviation, and inculcate holistic management culture that best achieve the established project investment value. Some project management application and implementation place more attention to the interests and objectives during construction phase, but not according adequate consideration toward whether the whole process of construction project implementation management meets the investment objectives, long-term value and future use of the building and maintenance optimization (Zhou, 2002). The introduction of VM system into construction projects can be a good solution to achieve the initial investment objectives and provide investors a full life-cycle guarantee (Liu, 2006). Project owners can use VM as a benchmark to plan in entirety various construction projects and coordinate with all units involved in carrying out the work, guided by clear criteria and system for evaluating various issues, thus avoiding various problems of construction progress, construction wastage, quality and safety that affect the project value. This would also equip building owners with a systematic mechanism for comprehensively expounding, to various construction participating units, the construction investment objectives, and the research, analysis and treatment of the various construction related problems (such as schedule delays, quality issues and safety accidents, cost increase and design variation requests).

The above considerations also bring into light the primary duty and responsibility to be fulfilled by the project owner. Inducting VM approach can help the construction project owners to aptly perform their essential obligations and responsibilities in the construction process, positively impacting on the project. Combining this finding with real case experience and learning from international project management, the view is that: For effective control with the objective of realizing investment value and guaranteeing full life-cycle value as well as the consideration for the project owners to appropriately fulfill their responsibilities and obligations, there are great potential benefits to suitably consider inducting appropriate VM into the construction process for project implementation (Bal, Bryde, \& Ochieng, 2014). Emphasis should be to achieve, in the midst of needed integrated planning of and simultaneous attention to multiple large-scale projects under construction, maximization of investment values and optimization of individual projects, as well as the orderly development, cost savings, rational resource allocation and compatibility of large-area master development (Moh, Devaraj, Nicholson, Mitchell, Parashar, \& Sloan, 2007; Moh \& Kok, 2008).

\section{VM system for large-scale construction project}

Value engineering is a methodology for combining function, cost, technology and economy, thereby improving economic efficiency. An UK's architecture industrial technology research authority, BRE Building Research, indicates that in general, value engineering can reduce $10 \%$ to $15 \%$ of the total cost in construction projects, reaching up to $40 \%$ for the better cases, while the total expenditure on value engineering amount to only $0.5 \%$ or less of the project cost (UK Office of Government Commerce, 2007). $\mathrm{VM}$ is naturally becoming the primary methodology of construction management in the new development of green, intelligent high-performance and large-scale construction projects. With the recent international construction industry gradually progressing toward the development of intelligent buildings, green communities, internetworking, high technology buildings with special purpose and residency requirements etc., China's construction industry is in sync with international trends to expand the development and construction of intelligent and green, high-technology buildings. To ensure the buildings meet the owners' expectation of high standards after its completion, the building owners need inevitably intensify direct participation in construction management, and Value-based Project Management System opens the door for the owners to achieve this goal. VM in China's 
construction industry is relatively in its early application stage, having not been widely put into practical application in management by many investment parties (Zhang \& Wei, 2009). Taking into account China's new round of infra structure construction and policy guidance on domestic demand promotion in the new era, the application of value engineering in construction management seems significant (Zhang \& Ban, 2011). For large-scale projects, especially for large municipal and public government investment projects, the project owners more so ought to apply valuebased project management approach, so as to optimize the investment value and safeguard full life-cycle value of the project. Under normal circumstances, the project owner often subjectively sets the overall construction investment goals, on the basis of which the requirements and targets of the specific project are determined. The owner could, however, appoint a value manager as the principal executor of VM for the project. This value manager can set up a project VM team from among all participating units of the project construction, and through regular meetings conversed with representatives of all participating units and other modus operandi undertake the VM works of the project. From the commencement of preliminary design, design development, construction drawing review, bidding, cost review, and the whole construction process until completion acceptance, every stage ought to closely undergo VM and control. Figure 1 shows the application of VM system's operation processes: The solid line depicts a typical traditional construction project process, and the dotted line depicts a new value-based management system process. The value manager responsible for directing the VM works would focus on value realization and safeguarding of life-cycle investment value, fully implementing the VM concept and the associated analysis and monitoring of all works related to the whole project construction process.

For a more intuitive explanation, we can refer to a typical example of VM carried out in the advanced countries and regions. For example, Nottinghamshire Community Arts Center construction project was one of 12 major government investment projects in the UK government's annual program. Our lead author (Zhao \& Chen, 2015) had been involved in the pre-planning and organization of this construction project. The project comprised of a number of civil sub-projects including old road reconstruction within its Red Line Zone, City Plaza extension and cultural center reconstruction etc. The new buildings covered a total construction floor area of nearly $100,000 \mathrm{~m}^{2}$, involving a total budget of about 80 million GBP. Nottinghamshire's annual construction aim was to improve the region's cultural environment and optimize the public facility layouts. The goal set by the local council as project

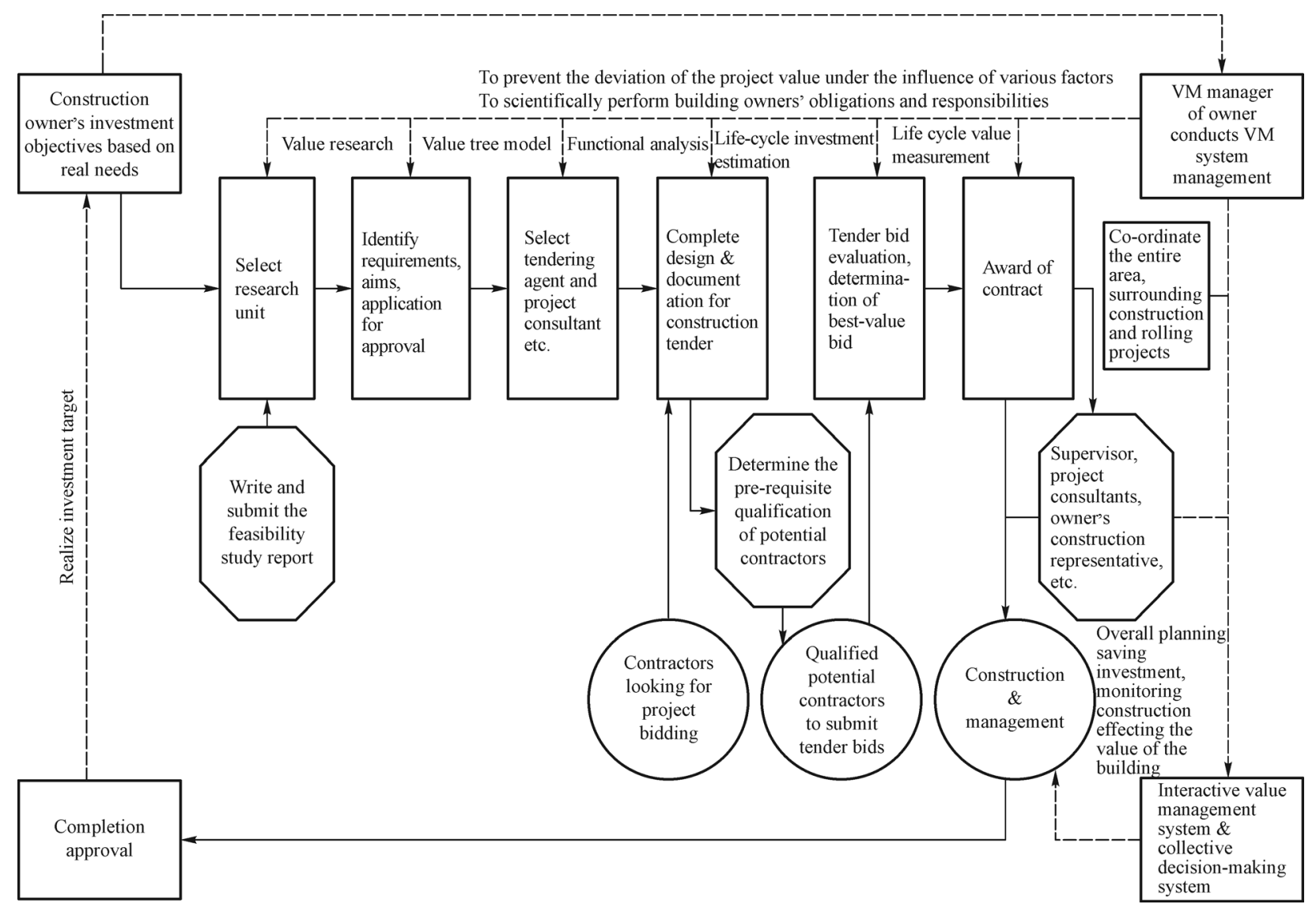

Figure 1. Process diagram of VM by building owners. 
owner was to develop, after referring to the arrangements of all relevant governmental construction projects, a coordinated plan for the various sub-projects, setting reasonable construction time-lines to carry out the reconstruction works, while minimizing disruption to local residents and their usage of the existing facilities. The project budget was very tight, hence the owner needed to save on costs, in order to ensure that the project wouldn't be interrupted due to budget overrun. The governmentinvested project was undertaken by a main contractor. Stemmed from a variety of considerations, implementation of value-based management enabled the project owner to better ensure the smooth execution of the reconstruction. Through implementation of VM, the sequencing and progress of various sub-projects were effectively planned, thereby reducing the project cost by nearly $40 \%$. Consequent to use of VM throughout the project, the reconstruction process of Nottinghamshire Community Arts Center was given good commendations and the completed works smoothly obtained government's acceptance, thanks to high-quality construction and realization of better value of the project. This also resulted in the project ultimately winning the British Royal Institute of Architects RIBA award.

\section{Green building development survey}

By the end of 2013, China had certified 1,446 green buildings, with a total floor area of nearly $163 \times 10^{6} \mathrm{~m}^{2}$. The number of certified buildings in 2013 itself was an $81 \%$ increase over 2012, and an increase of 1.12 times in floor area. By 2020, city-township's green buildings as a proportion of new buildings are expected to grow from $2 \%$ in 2012 to $50 \%$ in 2020 , and the construction industry will soon usher in the era of large-scale development by leaps and bounds. The revision work of Evaluation Standard for Green Building, GB/T50378-2006 (China Construction Ministry, 2006), which has been put into practice for eight years, has been officially completed. Recently, the Ministry of Housing and Urban-Rural Construction announced approval of Evaluation Standard for Green Building as the national standard, number GB/ T50378-2014, effective from January 1, 2015. The original Evaluation Standard for Green Building has been repealed simultaneously. With regards to the existing emphasis in the green building industry on individual application of material technology, and with regards to technology integration especially pertaining to its inadequate operational integration with the buildings' functions, the evaluation criteria have included the addition of "bonus items" to encourage improvement and innovation of green building management. Evaluation criteria are also being developed toward a more quantitative, objective and scientific direction, changing the ranking system from summation of branch scores to that of itemized scores. The new evaluation criteria have added items on construction management, reflecting the whole process control of green buildings with associated new requirements for construction management (Gao, Wang, \& Yu, 2014). In this regards, the promotion of China's green building industry development needs not only be limited to the continued improvement and upgrading of laws and regulations related to evaluation criteria, etc., but also research efforts for new breakthroughs in the implementation and management practices to be adapted for a new round of development of the construction industry. This is not only conducive to promote the development of green building industry, but also to provide the tools for resolving the issues of inadequate drive for technology innovations, inadequate application integration and challenges of construction management which are surfaced in the process of industrial development of green building. The new evaluation criteria are demarcated into design evaluation and operational evaluation, expanding attention and assessment on the whole life-cycle value. The change of these evaluation criteria also reflects the gradual trend toward emphasis on value evaluation, further promoting the induction and popularization of VM for green building projects.

The progress in the development of green buildings around the country is at different levels and status, but all are actively promoting green buildings. For example, in Guangzhou, according to the "Approval for Consent to Conduct One-star Green Building Evaluation Works in Guangzhou by the Guangdong Provincial Department of Housing and Urban-Rural Construction (Guangdong Construction and Technology Letters, No. 881, 2014)" (Guangdong Provincial Department of Housing and Urban-Rural Construction, 2014) and the "Guangzhou Green Building and Building Energy-saving Regulations (Guangzhou Municipal Government Orders, No. 092, 2013)" (Guangzhou Municipal Government, 2013), the Guangzhou Municipal Urban and Rural Construction Commission issued a notice to the local construction administrative departments to undertake the assessment process for implementing the requirements of the Guangzhou Area's Green Building Design Mark (GB and provincial standard one-star), the Project Completion Mark (one to three stars) and the Operation Mark (GB and provincial standard one star) from June 1, 2014. The government administration has introduced green building assessments as an accelerator to further promote green building development. However, there is corresponding need for equal attention to establish a robust management system related to green building process. As can be expected, with continued development of green buildings in the country, in addition to considerations for achieving their investment value and whole life-cycle value, induction of value-based management approach will effectively enhance the project value of green buildings. This will in turn help to successfully imbibe the philosophy of project value maximization in green building investment into the 
mindset of the project owners, whose active commitments to fulfill their associated obligations and responsibilities are essential for project success (Zhuang \& Bao, 2011). The following sections describe the main advantages of valuebased management system, illustrated by specific examples of the implementation process and real-case analysis, for future peer reference and mutual learning in developing green building projects.

\section{Process of VM for green building construction}

VM is a scientific methodology of information collection, analysis, selection, confirmation. It can be applied to the entire management process of green building project design, construction, operation upon completion, and maintenance. Figure 2 shows the process diagram for green building VM. It can be broadly divided into six stages.

\subsection{First stage: Planning}

The main task of this stage is to set up in conjunction with the relevant parties, a VM team, and define its main responsibilities and authorities. Qualified VM personnel will usually be the VM team leader, usually appointed by the owner and given the authority to undertake the VM works. The competence level of VM team leader is a key factor for its successful execution. The main work in this phase include the followings: 1) Request for nominations and selection of the representatives from the concerned parties to establish the VM team, targeted candidates being mainly from owners, developers, construction representative units ("dai-jian" in Chinese), project managers, contractors, green and sustainable consulting units, design units, and other related guidance personnel on VM;2) VM workshops will be held by the VM team, to affirm membership of the VM team and its structure, and to define the principal responsibility and authority of the VM team; 3) information collection: The responsible value manager should, while consistently maintaining a sober perspective, guide the management team to set their initial targets as well as determine needed information for the value analysis process so as to support all design and construction management units in their decision making; 4) the VM team will invite various units including cost consulting units, supervision units, manufacturers, suppliers and other units involved in the project construction, to participate in special subject discussions of VM, to ensure that all parties

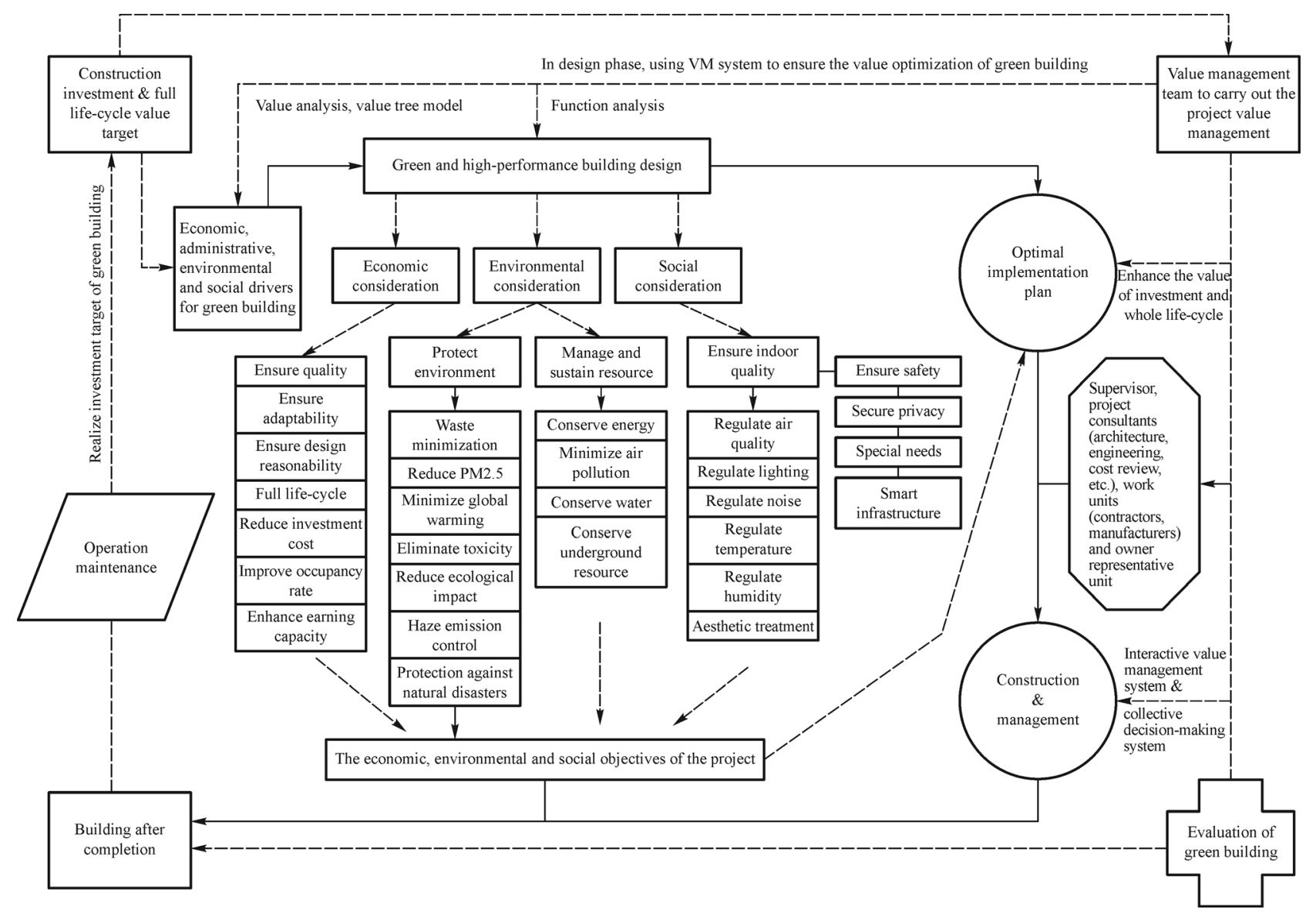

Figure 2. The implementation diagram of the value management of green building projects. 
agree with the initial targets set at the planning phase and the collected information is relevant and factually correct.

\subsection{Second stage: Validation}

The main work of this stage is for the VM team to define the specific scope and objectives of VM, involving the project's participating units in specific subject meetings for consultation and confirmation. The VM team will summarize the reasons for applying green building technologies in the design and construction process, and submit them to the relevant investors and owners for their support, for the implementation of green building elements in the project. The application of a green building technology implementation process must become one of the goals. The related contents and details shall be determined prior to the development of design and construction plan, and be submitted to the potentially relevant impacted units for review and consent. These related units include owners, investors, developers, construction design institutes, engineering consulting units, the Planning Board, material suppliers and manufacturers and other parties involved in the whole process of project construction and postcompletion, bearing in view of the full life-cycle value as the reference for consideration of the review under this section.

\subsection{Third stage: Analysis}

The main work of this stage is the synthesis of the main principles of green building into the building functions, for conversion into a series of information and instructions for the associated green building technology application. During the design phase (or construction stages of the design changes), the VM team can apply functional analysis (FA) techniques. FA is considered to be the core of VM with regards to design works, a solution technique capable of identifying and differentiating a variety of issues. It also enhances the project management team's understanding of the project and provides the analytical basis for their innovations to resolve various problems. There are various techniques of FA. Some are very structured, such as, the widely used functional analysis system technology (FAST) in the United States; others are relatively informal, such as, the value tree technique for modeling project functions. The VM team can in this analysis phase define the green building principles by the use of functional operation analysis methods, to guide future VM works of the project. FA can quickly filter a wide variety of demands for the building. Thus after FA, the main functions of the building can be more prominently featured. During the construction phase (or design phase conceptual design stage), the VM team can, via the interactive VM set-up for the collective decision-making system, simultaneously attend to the integrated planning and analysis of construction status of the overall project, its peripheral considerations and rolling programs as well as the various sub-programs within the project that impact the value of the building. This provides the analytic basis for selection of innovative solutions to resolve construction problems and implementation challenges. Specifically, the VM process in its design and construction applications will enhance the green building construction work. This includes the following three steps.

Step A: Problem identification. Identification and definition of problems is a necessary condition precedent for VM. As the basic requirement to achieve the project objectives, the project management team will need to identify and define the problem to be tackled by the induction of the VM system. During the design phase, the main problems are whether the main functionalities of the project can achieve the expected project objectives of the owner. During the construction phase, the main problems are whether the construction optimization schemes of the project can simultaneously attend to the integrated planning and analysis of the overall project, its peripheral considerations and rolling programs as well as the various sub-programs within the project, and systematically develop the best optimized construction schemes to enhance the value of the project.

Step B: Classification. This step is to promote the analysis procedure thereby moving from problem identification to classification into two groups: Primary and secondary categories. During the design phase, the problem can be divided into main and secondary functions. The primary function points mainly to the reason for the design of the building and the basic functions required for achieving the building project objectives. The secondary function refers to other functions required for supporting the primary functions of the project. During the construction phase, the problem can be divided into main factors and secondary factors. The main factors refer to primary factors affecting project building value as well as those required for achieving the project objectives. The secondary factors are the other factors for the realization of the primary factors above. The design functions and construction factors should be classified into "must have," "aesthetic needs," "peripheral social needs," and "noncritical demands," for reference by the VM team participating in the analysis and evaluation process.

Step C: Program indication diagram. This step is to describe the relationships among the various design functions and construction factors through the use of FA systems and interactive technology value-based management system. These help to provide the standard schematic diagrams inter-relating the various design functions of the building with the various construction factors.

\subsection{Fourth stage: The program}

The main task of this phase is to, by brain storming 
sessions, generate and examine a number of programs for project VM taking into consideration the various design functions and construction factors. Studies have shown that in the process of producing the programs, the design team should consistently adhere to sustainability building principles. This is a process of creative effort. And the advantages and disadvantages of each program will be evaluated and developed in subsequent stages.

\subsection{Fifth stage: Evaluation}

This stage consists of two main steps. The main task of the first step is to integrate the programs and concepts from the previous stages, and summarize the feasibility and sustainability of various proposals. The main task of the second step is to determine and select VM evaluation criteria to judge and select the best two alternative programs, for comparison in the selection of the best program for implementation. All the proposed programs are to be assessed with respect to the design features and construction factors earlier identified for the project. The information of the programs under comparison should as far as possible be quantified or practically described, so that the design teams and the various units involved in project construction can rationally evaluate their feasibility and implementation suitability. The program description should cover the superiority and reasons for the program, the analysis of advantages and disadvantages, and the necessary conditions for the implementation of the program, including estimated investment, life-cycle costs, implementation costs, and other construction problems associated with elements of green building construction. Evaluation process typically includes the following steps: 1) The elimination of non-feasible programs; 2) the integration of similar programs into groups, for example, electrical, electronics, construction, materials, landscaping; 3 ) in each group, the programs will be ranked by means of statistic, numerical evaluation, team voting and other techniques, based on priority evaluation criteria.

\subsection{Sixth stage: Implementation}

The main task of this stage is to determine how the optimal program will be implemented, and to manage, control and provide information feedback on the implementation process, to ensure smooth and efficient implementation of the program. If new situations and new problems surface in the process of implementing the program but are classified as minor ones which do not affect its overall implementation, the VM team will make needed adjustments to optimize the program while continuing its implementation until completion. If serious new situations and problems emerge with significant impacts on its overall implementation, the VM team shall deal with the new problems and revert to the second stage (validation stage) for renewed analysis, program generation, evaluation, implementation, to ensure the successful implementation of the project until completion.

\section{Real-case applications}

Two case examples with the lead author's personal involvements are outlined below for reference.

6.1 Case example of planning and design phase of VM: SIPO Patent Examination Guangdong Cooperation Center in Guangzhou Knowledge City

SIPO Patent Examination Cooperation Center is an institution directly under the State Intellectual Property Office. The SIPO Guangdong Center was established in 2011, and this project is to build the center's permanent business premises in the Southern Start-up Area of the Guangzhou knowledge city. The business premises need to meet the functions of their patent examination, hires and job training, business seminars and exchange visits of experts and other business functions. They also need to be equipped with a sports area, dining area, underground parking and public facilities, etc. It will be built to provide the capacity for 2,000 or so patent examiners and 120 management personnel to carry out the work required. Guidelines include building density not more than 30\%, volume ratio not more than 2.0 , green rate not less than $30 \%$, building height not more than $45 \mathrm{~m}$. Total floor area is $130,000 \mathrm{~m}^{2}$, including $80,000 \mathrm{~m}^{2}$ for Phase 1 . The expected total investment is 600 million CNY. The green building design objective of this project is to achieve national green building design standard of two-star level. Special subjects VM workshops were organized to address matters of land conservation for the project, energy conservation, water conservation, resource conservation, indoor and outdoor environmental quality control, and related operation management, and all aspects needing to be upgraded overall in accordance with green building design standards. The main focus was the application of value analysis approach for design management of two business office buildings, one comprehensive service office building, one administrative services building, the sky-light roofing of the conference center, wall materials, HVAC, plumbing, electrical, lighting and energy consumption of the project. At the special subjects VM workshops, the responsible persons leading the workshops, using exhibited design charts, investigation results and collected site information, facilitated the examination of the design plans through free open consultations. The main tasks of the special subject's workshops were the review of the original design, gathering of information related to VM, feasibility analysis of project supervision, and technical and economic considerations in accordance with value investment and life-cycle value concepts, affirmation of value-based green building elements and technologies, and development of 
value-based innovative solutions. Other tasks of the special subject workshops included the verification of key stakeholders, critical project functions and factors, advantages, disadvantages and risks of different programs, duration of the execution timelines, cost budget and value enhancement opportunities. After using the value tree analysis and function research analysis methods, the project design of SIPO Center is able to, as compared to buildings of similar scale, effectively achieve the following: Reduction of construction cost by $20 \%$; increased green building features, increase in elements of technology by $30 \%$; an increase of $35 \%$ incapacity-building investment income, the realization of better full life-cycle value, and provision of a good technology platform for VM during the construction stage and post-completion operation of this green building project.

6.2 Case example of construction phase of VM: Guangzhou Bioisland Standard Industrial Unit (Phase II) project

The Bioisland Second Phase is located in the west of Guangzhou International Bio-island planning C14 road, with a total land area of $30,575 \mathrm{~m}^{2}$ and a total floor area of $81,000 \mathrm{~m}^{2}$. At the end of May 2011, it officially started construction, and was fully completed by August 2013. The project includes an integrated basement under four buildings, which are an 8-storey R\&D production building, an 8-storey R\&D office building, a 7-storyproduction building, and a 6-storey R\&D pilot development plant. The project encompasses the GMP standard production plant as required for biomedical $\mathrm{R} \& \mathrm{D}$, built jointly with the biochemistry laboratory building and the R\&D office building over the same land parcel. The project fully considers green building technology, and consists of highperformance special-purpose buildings. Its basement has a clear height of $5.1 \mathrm{~m}$, divided into R\&D office buildings, manufacturing plants and R\&D pilot plant basement, and basement production space entailing total basement construction areas of $16,000 \mathrm{~m}^{2}$. Key construction considerations include the excavation to depth of $6.1 \mathrm{~m}$ over a total area of $16,000 \mathrm{~m}^{2}$, involving cement-mixed piles, anchored excavation works and jet-grouted caisson pile construction, erection of support heights of $24 \mathrm{~m}$ spanning over $15 \mathrm{~m}$ high formworks for construction. Concurrently under construction with the Bioisland Second Phase Project were the Bioisland Third Phase with a total construction floor area of $104,000 \mathrm{~m}^{2}$ and the Bioisland Corporate HQ with a total construction floor area of $170,000 \mathrm{~m}^{2}$. And there was the newly completed Bioisland First Phase with a constructed floor area of 53,000 $\mathrm{m}^{2}$. To build the Bioisland Second Phase, the Bioisland Company as the project owner commissioned the Project Construction Representative and the cost consulting units, in order to expeditiously and accurately understand the building professional issues, and to make accurate judgments and correct decisions in the midst of various problems faced in the construction process, with involvement of the professional construction departments and agencies. Although limited by policies and administrative positions to establish the value manager post, the project owner successfully introduced, mainly through the management process, the concept of VM to all construction units. The project owner clearly defined the design concept, quality and value targets of the Bioisland Second Phase project, established a set of evaluation criteria for treatment of various issues, and demarcated the division of responsibility among the project team units. In practice, in the process the project implementation, the project owner used primarily an interactive value-based management system. This involved information collection from the construction site and participating units, and information organization and analysis thereafter. Regular meetings were held with responsible representatives of various participating units, to carry out the assessment of the project value and VM communication. And in particular, to strengthen the coordinating role of supervision in the VM of the project, improving effectiveness and tapping on their strengths in project supervision. During the critical stage of meeting completion schedules, in order to streamline and clearly demarcate the roles and responsibilities of the participating parties and to accelerate the construction of Bioisland Second Phase project, a special project VM workshop was held by the project owner to collect information on new changes and new problems arising during construction, and to evaluate and determine these changes and problems, together with the responsible representatives of the preceding and current construction representative units, design units, construction units, supervision units, cost consulting units, and the external power construction units, and other experts and consultants. The techniques of Group Decision Support System (GDSS) and Interactive VM System (IVMS) were used to organize the views and conduct due analysis, and decided in consultation all workshop participants the following: 1) Implement the project in line with project owner's VM concept; 2) clearly define the responsibility and authority of all units, and particularly with regards to a previous change of the entrusted project management unit in August 2012 from the original Bioisland Guangzhou Development Zone to the Guangzhou Development District Construction Management Center, clearly demarcate the responsibility and authority between the two units; 3) set up a clear audit process and feedback mechanism with specified response timelines to accelerate the speed of change management and budget review; 4) once again, jointly with the Construction Management Center and the construction units of both the Biologic Garden Phases 2 and 3 projects, further confirm the progress mile-stones and construction organizations, scientifically coordinating with the surrounding construction projects to avoid construction wastage and minimize time loss due to delay in construction progress and submission reviews; 5) accelerate the construction schedule to safeguard the overall economic 
benefits of the region and to maximize the overall economic value of the project. In addition, for design and construction issues affecting the project value, the project owner would be directly involved in driving the process. After organizing the research and analysis of this workshop, the lead author in collaboration with the various units' representatives drew up the plan to resolve all the problems, and thereafter coordinated and tracked the project implementation. The design-change escalation procedures reviewed at the workshop were basically approved and completed in collaboration with various participating units within two weeks after the workshop, and the project implementation reflected an acceleration trend. By July 2013, the main contractor had achieved the critical milestones as planned and full completion was achieved by August 2013. The project was judged as an exemplary safe and civilized model of a construction site in Guangzhou. The construction targets were fundamentally achieved. The goals of value investment and whole lifecycle value have been well realized.

\section{Conclusions}

In undertaking, during recent years, project design and construction management works, it has been realized that the implementation of value-based management is an effective means of scientific management of large-scale construction projects and green building projects. In driving to achieve the investment value and realize the whole life-cycle value, building owners ought to conscientiously fulfill their obligations and responsibilities associated with the introduction of value-based management approach, exemplifying their commitment of value investment philosophy over the entire construction process. VM can efficaciously transform the traditional project management processes and positively supplement their value creation. In addition, in tandem with China's progress in setting the green building rating guidelines and administrative regulations, there is the corresponding need for effective VM system for green building. Following the traditional design and construction management models is inadequate to fully tackle the new challenges encountered in the process of developing green buildings, especially for large-scale complex projects. The introduction of value-based management will undoubtedly be a good solution to overcome these challenges, thereby promoting robust development of the green building industry.

Real case examples also show that for the smooth development of VM works, owners first need to seriously commit their direct involvement and participation in the management of construction projects; secondly, owners need to be familiar with the building policy and technical rules, which usually require specialized institutional support to help in knowledge-based problem solving; and finally the owners have to communicate and leadimplement the VM philosophy with all participating units of the project. These will enable the project supervision unit to more constructively perform their coordination and oversight roles.

In conclusion, VM will help to reduce the project cost and enhance economic values. It facilitates the integrated coordination among the participating units and the surrounding interacting parties to attain optimal construction plan, minimize wastages and improve the quality of works and progress, setting all parties toward one common goal of shared benefits. In doing so, optimum project values and maximized whole-life project benefits are achieved.

\section{References}

Bal, M., Bryde, D. B., \& Ochieng, E. (2014). A critical review of integrated project management for construction sustainability, In: Proceedings of the 2014 International Conference on Economics, Management and Development (ICEMD 2014). 53-61.

Gao, D., Wang, Y., \& Yu, Z. (2014). A review on drafting of construction management chapter in latest revision of evaluation standard for green building. In: Proceedings of the 10th International Green Building and Building Energy Saving Conference (in Chinese).

Guangdong Provincial Department of Housing and Urban-Rural Construction. (2014). Approval for consent to conduct one-star green building evaluation works in Guangzhou by the Guangdong Provincial Department of Housing and Urban-Rural Construction (Guangdong Construction and Technology Letters, No. 881, 2014). Guangzhou: Guangdong Provincial Department of Housing and Urban-Rural Construction (in Chinese).

Guangzhou Municipal Government. (2013). Guangzhou green building and building energy-saving regulations (Guangzhou Municipal Government Orders, No. 092, 2013). Guangzhou: Guangzhou Municipal Government (in Chinese).

Jiang, B., Cheng, Z., Gao, D., Guo, Z., \& Deng, G. (2013). Comparative analysis on BREEAM and domestic evaluation standard for green construction. Quality Engineering, (10), 32-36 (in Chinese).

Liu, G., \& Li, J. (2008). Improving the efficiency of building industry based on value management: Overseas experience and reference. Modern Management Science, (3), 24-26 (in Chinese).

Liu, W. (2006). Simply talking about application of value management at stage of building engineering design. Northern Communications, (8), 82-84 (in Chinese).

McGraw Hill Construction. (2013). World Green Building Trends. McGraw Hill Construction.

Ministry of Construction. (2006). Evaluation Standard for Green Building (GB/T50378-2006). Beijing: China Construction Press (in Chinese).

Ministry of Housing and Urban-Rural Construction. (2014). Evaluation Standard for Green Building (GB/T50378-2014). Beijing: China Construction Press (in Chinese).

Moh, W. H., Devaraj, S., Nicholson, G., Mitchell, R., Parashar, S., \& Sloan, E. (2007). Performance monitoring of deep excavation at 
Changi WRP Project, Singapore. In: Proceedings of 7 th Field Measurements in Geomechanics. ASCE Library, 1-12.

Moh, W. H., \& Koh, S. T. (2008). Achieving value in water projects through partnership. Water Practice and Technology, 3(4), wpt2008097.

SAVE International. (2007). Value methodology standard. SAVE International.

Shi, L. (2014). Discussion on the application of value engineering in construction project management. Shanxi Architecture, (14), 270-271 (in Chinese).

Tong, X. (2008). Value management and value engineering in our country. Infrastructures Construction Management Optimization, (1), 34-37 (in Chinese).

UK Office of Government Commerce. (2007). Value management in construction: Studies case. London: OGC.

Wang, L., \& Yuan, Y. (2011). Research in investment decision of green buildings based on the value engineering. Value Engineering, (01), 26-27 (in Chinese).

Xue, H. (2012). Application of value engineering theory in investment decision of green building. Architecture (Washington, D.C.), (3), 6667 (in Chinese).

Yan, J., Zheng, C., Wang, Z., \& Gu, M. (2013). Cost of green houses based on value engineering. Energy Efficiency Economics, (9), 72-74 (in Chinese).

Zhang, J., \& Ban, Y. (2011). Research on the comprehensive value management system of large scale construction project. Modern Economic Information, (5), 45-46 (in Chinese).

Zhang, Q., \& Wei, C. (2009). Discussion on the value management in construction projects. Journal of Shandong Jianzhu University, (4), 346-349 (in Chinese).

Zhao, R., \& Chen, X. (2014). Global green building development trends and China's situation. Shanxi Architecture, 23, 235-238, (in Chinese)

Zhou, S. (2002). Application of value management method in construction project management. Construction Supervision, (6), 60-61 (in Chinese).

Zhuang, H., \& Bao, H. (2011). Cost control and value promotion of low carbon housing based on value engineering. Knowledge Economy, (5), 12-13 (in Chinese). 